\title{
Why the caregivers of bipolar patients need to be in constant touch with a physician: A qualitative study of text messages from patient caregivers to a physician
}

\author{
Ruohollah Seddigh ${ }^{1}$, Amir-Abbas Keshavarz-Akhlaghi', Somayeh Azarnik ${ }^{2}$, Sara Bahrmpour ${ }^{3}$, Behnam Shariati ${ }^{1}$
}

\begin{abstract}
Background: The variety of caregiver's needs of bipolar patients signifies the importance of performing dedicated interventions to help this group of caregivers based on the cultural conditions of the country in which they live; the present study therefore seeks to address this issue through a different method.

Methods: The families of 28 patients with bipolar disorder type 1 who were treated for at least two months by a single psychiatrist gradually entered the study over a six-month period. They received the phone number of the psychiatrist in attendance as soon as the patient was in remission according to the same psychiatrist's interview. A total of 1908 texts were sent and received and each family sent an average of 68.14 text messages during the three years, with the minimum being 40 and the maximum 83 . All the text messages were transcribed verbatim and were evaluated by three faculty members through the qualitative content analysis method.

Results: In this study we found three themes and there were some codes in each theme.

1. The first theme was "Training" which the caregivers requested advice about symptoms and tests, the course of the disease, assurance, medication side-effects and their management, how to stop smoking, how to control high-risk behaviors and double checking appointments with the physician, making for a total of 1079 text messages received.

2. The second theme was "Reporting" which contained a description of emergency symptoms and requesting advice, reporting response or no response to the medications, reporting medication adherence and dosage taken.

3. The third theme: "The expression of feelings" including the expression of gratitude, saying congratulations on national and other celebrations and expressing anger and hatred.

Conclusion: Overall, the caregivers of patients with bipolar disorder have many needs; meeting these needs affects the patients' outcome and the caregivers, but requires a greater attention by the healthcare team and it is necessary for these needs to be evaluated in the context of each distinct country.
\end{abstract}

Keywords: bipolar, caregiver, sms, qualitative study

\section{INTRODUCTION}

Studies conducted in Iran report the prevalence of psychiatric disorders as $10.8 \%$ to $34.4 \%(1,2)$ and the prevalence of bipolar disorder as $0.04 \%$ to $1 \%$ (3). The highly prevalent bipolar disorder is a condition that causes multiple disabilities and problems in domains such as cognition, getting along, life activities and participation $(4,5)$; taking care of bipolar patients is therefore associated with several difficulties and the caregivers of patients with this chronic disease report a relatively high prevalence of burden (6). The high prevalence of burden in caregivers of patients with bipolar disorder predisposes the caregiver to psychiatric disorders, physical problems, greater use of medical services, reduced social support and greater family conflicts (7-10). The main concerns of caregivers of these patients are related to annoying behaviors such as hyperactivity, irritability and depression in the patients and anxiety about their work, study and relationships. The caregivers were also concerned about the possible effects of this disease on their surroundings and health and about the severity of their patient's disease and medication adherence, the lack of support, the stigma

\footnotetext{
1 M.D. Assistant professor of psychiatry, Mental Health Research Center, Iran University of Medical Sciences, Tehran, Iran.

2 MA. Clinical psychology, Rajaee hospital, Tehran, Iran.

3 MA. Clinical psychology, Islamic Azad University, Science and Research Branch, Tehran, Iran
}

Correspondence: Behnam Shariati

MD., Assistant professor of psychiatry, Mental Health Research Center, Iran University of Medical Sciences, Tehran, Iran.

E-mail: Behnamshariatimd@gmail.com

Received: 14 Jun 2018, Accepted: 6 Oct 2018

(c) 2018 by the authors; licensee Modestum Ltd., UK. This article is an open access article distributed under the terms and conditions of the Creative Commons Attribution License (http://creativecommons.org/licenses/by/4.0/). 
associated with the disease and the resultant loneliness $(11,12)$. The caregivers felt that they needed to share their feelings with others so as to gain a better understanding of the disease and their conditions (13). They experience numerous conflicts and conflicting emotions and look for hope and seek to give meaning to their caregiving role; in other words, they are involved in an ethical challenge (14) and need the medical staff to notice their problems (15). In addition to financial problems, the caregiver's poor health conditions and the difficulty to manage the patient's symptoms, these problems make the caregiver more susceptible to psychiatric disorders, particularly depression (16). The variety of these needs signifies the importance of performing dedicated interventions to help this group of caregivers based on the cultural conditions of the country in which they live; the present study therefore seeks to address this issue through a different method.

\section{METHOD AND MATERIALS}

The families of 28 patients with bipolar disorder type 1 who were treated for at least two months by a single psychiatrist gradually entered the study over a six-month period. The patients' bipolar disorder diagnosis was ensured through a semi-structured SCID interview and they were disqualified if they had any comorbidities except for smoking dependence. The caregivers of the patients received the phone number of the psychiatrist in attendance (who was also a faculty member) as soon as the patient was in partial or full remission according to the same psychiatrist's interview. This caregiver was appointed to this job in a gathering of the patient's entire family and had to be able to send text messages and was allowed to text the psychiatrist day-and-night with any questions or comments that came up. The psychiatrist in attendance was to reply to all the texts in less than two hours and this arrangement continued for three years and each family benefited from these services for three years from the time they entered the research; it should be noted that almost all the patients had been selected within three months of beginning the study. Of the total of 28 patients, 20 were female and eight were male, including 12 mothers, three wives, five sisters, four fathers, two husbands and two brothers, and their age ranged from 20 to 62 . A total of 1908 texts were sent and received and each family sent an average of 68.14 text messages during the three years, with the minimum being 40 and the maximum 83 . The maximum characters in each text were 160 , consisting of three short sentences and at least ten characters on average. Each text consisted of an average of 100 characters, comprising of two short sentences. Each text cost about 160 IRR, to be paid to the telecommunication company, and the psychiatrist provided all the services free of charge. All the patients and caregivers verbally consented to participation in this research project. All the text messages were transcribed verbatim and were evaluated by three faculty members through the qualitative content analysis method of Graneheim and Lundman (2004).

\section{RESULTS}

\section{The First Theme: "Training"}

From the total of 28 caregivers, 18 ( 12 female and six male) requested this item. Concerning this theme, the caregivers requested advice about symptoms and tests, the course of the disease, assurance, medication side-effects and their management, how to stop smoking, how to control high-risk behaviors and double checking appointments with the physician, making for a total of 1079 text messages received:

\section{Code 1. Symptoms, tests and physiology of the disease}

A total of 220 text messages were received in this group, in which the caregivers requested mainly advice about symptoms, lithium-level tests and blood test; a few instances of these texts follow:

I contacted the doctor's office and they said there're no appointments until November. I have a question, do cortisol levels affect depression?

I'll send you my brother's test results. Please tell me if they're good!

Doctor, my husband has to go to the fruit and vegetable market at nights to get fresh herbs. Does staying up late harm him?

My mother has severe stuttering and tics. Do you think she has to be treated for them?

I don't know if I should continue it or not. Does it have any effects on his anxiety?

Twenty minutes ago, my brother had a kind of stroke-like episode and then got back to normal. This is not the first time this has happened. Is this okay? 


\section{Code 2. The course of the disease and assurance}

From the total of 150 text messages received on this subject, the caregivers requested mainly advice about the course of the exacerbation or improvement of the symptoms and their link with some stressors; these requests for advice sought a sort of assurance, suggesting that anxiety and uncertainty were very annoying for the caregivers:

When will my brother get better?

On the same day we visited you, a funeral was held for my brother's friend who'd committed suicide. Can he go to his grave? Can he attend his ceremony? He's in very poor health.

My daughter can't sleep; she is always feeling worried. We don't know what to do with her.

Mr. X hasn't yet been able to get him hospitalized. There are no empty beds at the hospital. Should we continue giving him the medications?

\section{Code 3. Learning about the medication side-effects and their management}

From the total of 352 text messages received in this area, the caregivers were concerned with the multiple side-effects of the medications given to their patient and about the relationship between the symptoms and the medications and their management; occasionally, they reported urgent cases; four of these cases were so dire that the physician had to call the caregivers on the phone to manage the complication.

I have an appointment with Dr. Y on November 29, but last week I went to see Dr. Z. He prescribed some pills. I believe now that the new pills have had some side-effects. Should I keep going to this doctor or not?

My brother takes Venlafaxine and is experiencing nausea and drowsiness as its side-effects. Is there anything we can do for him?

We've been out of his medications for four days now and he feels dizzy all the time. Sometimes he feels like he's collapsing.

My father has dandruff; he's gotten rid of them a few times, but they always come back. What should we do?

My mother got diarrhea today. Should she take anti-diarrhea pills? Can it be related to her lithium pills? What's your advice?

My brother has had fever and nausea for a week. He took Lamotrigine for 2-3 days before he began feeling this way. He stopped taking the drug, but he woke up today with his chest full of red spots and wheezing. What should I do for him?

The drug brochure says lithium causes tremors and diarrhea. Is it ok for him to take it?

My wife has developed sexual problems on this drug. I couldn't bring myself to tell you about it. Do you think it's for the drugs? Will she be okay?

My sister's breasts produce milk. Is it because of her drugs?

My mom suddenly stopped taking her pills and I think that her shortness of breath and body ache are for this. Are you available tomorrow?

Well, Navid says he is stressed and can't stop thinking about the past and can't concentrate.

\section{Code 4. How to stop smoking and its timing}

A total of 63 text messages were related to the subject of how to stop smoking and its timing and contained reports of increased smoking in the patients, concerns about the interference of smoking with the patients' medications and the patients' physical health:

My father has been smoking more. How can I reduce it?

My son has been smoking more. What do you think is the best way to deal with it?

My brother has been smoking more ever since you prescribed him Risperidone. What should we do?

My father has recently been discharged. Can he quit smoking now?

\section{Code 5. How to manage high-risk behaviors}

A total of 150 text messages were received on this subject, which were mainly concerned with suicide gestures, mild to moderate verbal and physical aggression in the patients and behaviors against the family norms:

What can we do with Aida and how can we deal with her? Can we do the punishment we talked about? She is threatening to commit suicide!

Would you please introduce a child psychology book to us?

Whatever we say, he gets easily angry. How should we deal with him?

My brother has several girlfriends and we're very upset about this. I think his sexual desire has increased! 
My son doesn't listen to us at all and stays out late. What can we do about him?

Parisa takes lithium and olanzapine and have been complaining of stiffness and pain in their foot for three days; they also behave aggressively. What should I do? They expect me to take care of their personal chores, and if I don't, they become aggressive. What should I do?

\section{Code 6. Training about high expressed emotion}

A total of 84 text messages were received on this subject, which pertained to the caregivers' concerns about the improper behaviors of other family members toward the patient and the effects of their behaviors on the patient's relapse and behaviors, and wanted the physician to visit the said family members in future appointments too and give the necessary advice:

Doctor, my son hasn't been speaking to my spouse for some time now. Should I bring him to you?

My father is always arguing with my sister. Do you advise that I bring him to you this time?

My older brother repeatedly picks on Saeed (the patient), telling him that he's fooling us with his illness. Should I tell him to come and visit you? I'm afraid Saeed's disease will come back.

My mother says to my ill sister, 'How much do you sleep? How lazy you are!' Is it ok to talk to her like that?

\section{Code 7. Double checking appointments with the physician}

A total of 60 text messages were received on this subject, in which the caregivers wanted to ensure the physician's presence on the day of their appointment or wanted to visit some other time due to some problems:

This Tuesday is a holiday. Will you be at the hospital?

Will you be at the hospital on Tuesday?

We couldn't get an appointment to see you this week. Can I bring my brother in for a visit some other day?

\section{The Second Theme: "Reporting"}

All of the 28 patients (10 men and 18 women) reported to the physician and a total of 675 text messages were received on this theme, containing a description of emergency symptoms and requesting advice, reporting response or no response to the medications, reporting medication adherence and dosage taken.

\section{Code 1. A description of emergency symptoms and requesting advice and hospitalization:}

A total of 191 text messages were received from the caregivers asking about the management of emergency symptoms, how to get admission for their patient and how to take him to the hospital and concerns about the availability of beds in the hospital, which eventually led to 14 cases of hospitalization during the three years.

Javad is not feeling well at all. I want to call an ambulance, but there are no empty beds in the hospital.

$\mathrm{He}$ is not feeling well enough to listen to us. He says he's not sick, he is delusional.

(B) My brother is feeling very bad right now and his obsession has intensified, he says he should do something to make his mind sound.

(B) Aida has attempted suicide again. Can we visit you tomorrow?

Saleh is not feeling well. He hasn't slept for 48 hours. What can I do?

My sister doesn't sleep at night, she's so talkative and repeats the same thing over and over again. Do you think we need to hospitalize her? And if we need to take her to Tehran, how should we go about it?

Doctor, my father is feeling really bad; he has strange thoughts. He's going crazy. I'm scared.

\section{Code 2. Reporting response to the medications}

In this sub-group, 86 texts were received about the improvement of symptoms, the expression of consent, grading the improvement of symptoms and return to work, family and social functions in the patient:

I'm feeling better today doctor, thank God. I'd almost lost my hope in life.

I'm feeling much better today. When I'm calm I study, and when I'm indifferent, I don't.

I'm feeling better ever since I started to take my pills at noon.

Ahmadreza is feeling well.

I'm always yawning. All in all, I'm a lot better.

I'm in a good mood. My energy levels haven't changed much.

I'm getting a little better and I can sleep better bit by bit.

I'm up since 4 am and can't go to sleep, I was good all in all, I'm less anxious, my mind is more at peace.

Saleh has started going to work again for a month now and has taken up exercise and he's feeling better. 


\section{Code 3. Reporting no response to the medications}

In the 93 text messages received in this group, the caregivers reported the lack of response to the medications and expressed their concern about this issue and requested to be informed about the onset of response to the medications:

I don't feel any different doctor. How long does it take for the medications to prove effective?

I've become more indifferent. I wake up from my sleep on and on. My mood hasn't changed much.

(B) My sleep has gotten much worse.

(B) I've not changed much.

I'm afraid to say my prayers, I know that if I do, I'll be all obsessed with it.

Aida is really bothering us. She keeps yelling.

Aida's behavior bothers us. She reports several physical symptoms.

I'm on Venlafaxine 37mg and I'm feeling nervous and I sleep much. My sexual problem is not resolved either. All in all, I don't feel good about this drug.

I don't learn anything from my music lessons and I've become more violent. What should I do?

Since I last talked to you about my problems, I feel too frail and walk slowly.

Dr. $X$ and Dr. $Y$ have done a lot for me all this time. But things keep changing as time goes by and it's difficult to bear all of that. I really don't know what to do.

\section{Code 4. Reporting medication adherence and dosage:}

A total of 230 text messages were received on this issue, reporting the caregivers' concerns about medication adherence, relative adherence and good adherence:

My mother's history is this: She's taking Citalopram and Levothyroxine and is currently feeling well, but she doesn't take sodium.

I should get on a plane on Friday and I wonder if I can call you on the phone. I ran out of my medications but am feeling well. I've so far taken my medications regularly.

My mother is angry with Dr. $\mathrm{X}$ for some reason and insists on not visiting him anymore, and she's not taking her medications anymore either.

\section{Code 5. Reporting on the medication dosage and asking approval for continuing the medication order:}

The 75 text messages received from the caregivers on this theme asked about how to continue and whether to decrease, increase or stop the medications and sometimes sought approval and guidance by the physician due to lacking fully drafted medication orders or the pharmacist's different opinion from the physician's on the prescription or the caregiver having forgotten the physician's orders:

Yesterday, I took a quarter of Risperidone and got drowsy. I take a quarter in the morning and a quarter in the evening. Should I continue?

Should I take my medications like before, doctor?

The nicotine patch is expensive. Can I buy the gum?

I'm taking three doses of Sertraline every day now and am feeling well. Should I continue?

We've left your medication order at the hospital. Would you please let me know how to take these medications: Olanzapine and Folic acid? I know how to take the rest.

\section{The Third Theme: "The Expression of Feelings"}

This theme consisted of the expression of gratitude, saying congratulations on national and other celebrations and expressing anger and hatred.

Of the 28 caregivers, 13 (eight male and five female) texted on this subject, making for a total of 154 text messages in which they expressed their gratitude and said congratulations on national and other celebrations and sometimes expressed their anger and hatred toward the physician:

\section{Code 1. The expression of gratitude}

A total of 64 text messages were received as gestures of gratitude toward the physician for his hard work, loyalty and commitment:

Amin has been feeling well for a while now and his symptoms are under control, thank you doctor.

Affection is neither forgotten nor lost; Happy New Year.

We've brought you some gifts. We'd like to see you tomorrow and offer them to you. 
I owe my recovery to your serene eyes. I'm a little spoiled now.

I wanted to say how thankful I am.

\section{Code 2. Congratulations on national and other celebrations}

A total of 46 text messages were received that congratulated on national and other celebrations and important days in Iran:

(B) Happy New Year! May I call you?

(B) Happy Yalda!

(B) Happy doctors' day to you kind doctor!

\section{Code 3. The expression of anger and hatred}

A total of 44 text messages were received from the caregivers that expressed feelings of anger, hatred, humiliation and disappointment toward the physician:

- When you said yesterday that I'm abusive in my relationships, I got very upset; it's not like that at all.

o You told my brother that he has a low IQ, but that's not the case at all. You don't really understand him.

o My husband is not a lab rat to do your experiments on, doctor.

o Don't feel bad, but I don't think you are well-educated.

o You were unable to help us, so we're taking him to our former doctor.

\section{DISCUSSION \& CONCLUSION}

Overall, the needs of the caregivers of patients with bipolar disorder can be classified into three categories:

1. Training: Training on symptoms, the course of the disease, medication side-effects and their management, how to control smoking, how to control high-risk behaviors, how to control the family's emotions and double checking appointments with the physician.

2. Reporting: Reporting on the patient's emergency symptoms, response or no response to the medications, medication adherence or non-adherence and medication dosage.

3. The expression of feelings: The expression positive and negative emotions.

The caregivers' need for training has also been frequently noted in other studies $(11,12)$ and studies suggest that training with a focus on giving information about the disease and teaching strategies to cope with negative feelings and how to manage the patients' behaviors affect both the patients' outcomes and the caregivers' health $(17,18)$. Previous studies have shown the importance of managing the expression of feelings on the outcome of bipolar patients $(18,19)$; sometimes, the caregivers requested advice from the physician on how to manage the expression of feelings by other family members involved in the patient's life. An interesting finding of the study is that Iranian caregivers need to double check appointments with their physician in order to ensure their presence and availability on the scheduled days, which may be indicative of the poor integration between hospital services and the community (20) and the deficient teamwork (21-23). In other words, in Iran, patients and caregivers are not followed up after discharge and research projects such as the present one that somehow fill this gap have proved significantly effective in reducing the caregivers' concerns (24, 25).

Several studies confirm the caregivers' need to report their patients' conditions and to build an ongoing relationship with the physician and to receive support from the healthcare team (26); in other words, concern about the integrity and continuity of services, information and support are reported as major concerns of caregive $(27,28)$. Nonetheless, some of these concerns pertain to dose verification and the lack of coordination between the pharmacist and the psychiatrist, indicating the poor teamwork among specialists (22) and suggesting the physician's or resident's lack of attention to the accurate drafting of medication orders to some extent; other studies have also reported missing medications in a prescription or incorrect medication doses as the most common medical errors $(29,30)$ that can be due to the great workload and the resultant fatigue in the healthcare team (31).

Finding a chance to express positive and negative feelings was another need of the caregivers, which suggests the cultural differences between Iran and the west. Iranians highly value those who have power and authority, such as physicians, and communicating and expressing feelings to them is a value among them (32). The expression of negative feelings to the physician can be due to the high prevalence of burden in these caregivers, which manifests itself through negative emotions (6). 
Overall, the caregivers of patients with bipolar disorder have many needs; meeting these needs affects the patients' outcome and the caregivers, but requires a greater attention by the healthcare team and it is necessary for these needs to be evaluated in the context of each distinct country.

\section{REFERENCES}

1. Mohammadi M-R, Davidian H, Noorbala AA, Malekafzali H, Naghavi HR, Pouretemad HR, et al. An epidemiological survey of psychiatric disorders in Iran. Clinical practice and epidemiology in mental health. 2005;1(1):16. https://doi.org/10.1186/1745-0179-1-16 PMid:16185355 PMCid:PMC1253522

2. Yousefi-Nooraie R, Farhoudian A, Amini H, Mohammadi M-R, Mesgarpour B, Mansouri N, et al. Prevalence of mental disorders among high-school students in Iran: a systematic review. Iranian Journal of Psychiatry. 2009;4(1):1-6.

3. Vandad Sharifi M, Hajebi A, Radgoodarzi R. Twelve-month prevalence and correlates of psychiatric disorders in Iran: The Iranian Mental Health Survey, 2011. Archives of Iranian medicine. 2015;18(2):76. PMid:25644794

4. Fountoulakis KN. Disability and Overall Burden Related with Bipolar Disorder. Bipolar Disorder: Springer;2015:361-88.

5. Guilera G, Gómez-Benito J, Pino Ó, Rojo E, Vieta E, Cuesta MJ, et al. Disability in bipolar I disorder: the 36-item world health organization disability assessment schedule 2.0. Journal of affective disorders. 2015;174:353-60. https://doi.org/10.1016/j.jad.2014.12.028 PMid:25553398

6. Perlick D, Clarkin JF, Sirey J, Raue P, Greenfield S, Struening E, et al. Burden experienced by care-givers of persons with bipolar affective disorder. The British Journal of Psychiatry. 1999;175(1):56-62. https://doi.org/10.1192/bjp.175.1.56 PMid:10621769

7. Perlick DA, Berk L, Kaczynski R, Gonzalez J, Link B, Dixon L, et al. Caregiver burden as a predictor of depression among family and friends who provide care for persons with bipolar disorder. Bipolar Disorders. 2016;18(2):18391. https://doi.org/10.1111/bdi.12379 PMid:27004622

8. Perlick DA, Rosenheck RA, Miklowitz DJ, Chessick C, Wolff N, Kaczynski R, et al. Prevalence and correlates of burden among caregivers of patients with bipolar disorder enrolled in the Systematic Treatment Enhancement Program for Bipolar Disorder. Bipolar Disorders. 2007;9(3):262-73. https://doi.org/10.1111/j.13995618.2007.00365.x PMid:17430301

9. Steele A, Maruyama N, Galynker I. Psychiatric symptoms in caregivers of patients with bipolar disorder: a review. Journal of affective disorders. 2010;121(1):10-21. https://doi.org/10.1016/j.jad.2009.04.020 PMid:19443040

10. von Kardorff E, Soltaninejad A, Kamali M, Eslami Shahrbabaki M. Family caregiver burden in mental illnesses: The case of affective disorders and schizophrenia-a qualitative exploratory study. Nordic journal of psychiatry. 2015:1-7.

11. Van der Voort T, Goossens P, Van Der Bijl J. Burden, coping and needs for support of caregivers for patients with a bipolar disorder: a systematic review. Journal of Psychiatric and Mental Health Nursing. 2007;14(7):679-87. https://doi.org/10.1111/j.1365-2850.2007.01158.x PMid:17880662

12. Reinares M, Vieta E, Colom F, Martinez-Aran A, Torrent C, Comes M, et al. What really matters to bipolar patients' caregivers: sources of family burden. Journal of affective disorders. 2006;94(1):157-63. https://doi.org/10.1016/j.jad.2006.04.022 PMid:16737741

13. Jönsson PD, Skärsäter I, Wijk H, Danielson E. Experience of living with a family member with bipolar disorder. International Journal of Mental Health Nursing. 2011;20(1):29-37. https://doi.org/10.1111/j.14470349.2010.00704.x PMid:21199242

14. Weimand BM, Hall-Lord ML, Sällström C, Hedelin B. Life-sharing experiences of relatives of persons with severe mental illness-a phenomenographic study. Scandinavian journal of caring sciences. 2013;27(1):99-107. https://doi.org/10.1111/j.1471-6712.2012.01007.x PMid:22583154

15. Rusner M, Carlsson G, Brunt $D$, Nyström M. Towards a more liveable life for close relatives of individuals diagnosed with bipolar disorder. International journal of mental health nursing. 2013;22(2):162-9. https://doi.org/10.1111/j.1447-0349.2012.00852.x PMid:22712875

16. Cummings SM, Kropf NP. Predictors of depression among caregivers of older adults with severe mental illness. Journal of gerontological social work. 2015;58(3):253-71. https://doi.org/10.1080/01634372.2014.978927 PMid:25357014 
17. Reinares M, Colom F, Sánchez-Moreno J, Torrent C, Martínez-Arán A, Comes M, et al. Impact of caregiver group psychoeducation on the course and outcome of bipolar patients in remission: a randomized controlled trial. Bipolar disorders. 2008;10(4):511-9. https://doi.org/10.1111/j.1399-5618.2008.00588.x PMid:18452447

18. Reinares M, Bonnín C, Hidalgo-Mazzei D, Sánchez-Moreno J, Colom F, Vieta E. The role of family interventions in bipolar disorder: A systematic review. Clinical psychology review. 2016;43:47-57. https://doi.org/10.1016/j.cpr.2015.11.010 PMid:26691629

19. Honig A, Hofman A, Rozendaal N, Dingemans P. Psycho-education in bipolar disorder: effect on expressed emotion. Psychiatry research. 1997;72(1):17-22. https://doi.org/10.1016/S0165-1781(97)00072-3

20. Moradi-Lakeh M, Vosoogh-Moghaddam A. Health Sector Evolution Plan in Iran; equity and sustainability concerns. International journal of health policy and management. 2015;4(10):637. https://doi.org/10.15171/ijhpm.2015.160 PMid:26673172 PMCid:PMC4594102

21. Aarabi A, Cheraghi MA, Ghiyasvandian S. Factors effecting on involvement of nurse leaders in policy making for nursing in Iran: a qualitative study. International Journal of Advanced Nursing Studies. 2014;3(1):53.

22. Irajpour A, Alavi M, Abdoli S, Saberizafarghandi MB. Challenges of interprofessional collaboration in Iranian mental health services: A qualitative investigation. Iranian journal of nursing and midwifery research. 2012;17(2).

23. Mahdizadeh M, Heydari A, Moonaghi HK. A Review of the Clinical Interdisciplinary Collaboration among Nurses and Physicians. Open Journal of Nursing. 2015;5(07):654. https://doi.org/10.4236/ojn.2015.57069

24. Malakouti Sk, Nojomi M, Mirabzadeh A, Mottaghipour Y, Zahiroddin A, Kangrani HM. A Comparative Study of Nurses as Case Manager and Telephone Follow-up on Clinical Outcomes of Patients with Severe Mental IIIness. Iranian journal of medical sciences. 2016;41(1):19. PMid:26722141

25. Sharifi V, Tehranidoost M, Yunesian M, Amini H, Mohammadi M, Roudsari MJ. Effectiveness of a low-intensity home-based aftercare for patients with severe mental disorders: A 12-month randomized controlled study. Community mental health journal. 2012;48(6):766-70. https://doi.org/10.1007/s10597-012-9516-z PMid:22772746

26. Yesufu-Udechuku A, Harrison B, Mayo-Wilson E, Young N, Woodhams P, Shiers D, et al. Interventions to improve the experience of caring for people with severe mental illness: systematic review and meta-analysis. The British Journal of Psychiatry. 2015;206(4):268-74. https://doi.org/10.1192/bjp.bp.114.147561 PMid:25833867

27. Valentini J, Ruppert D, Magez J, Stegbauer C, Bramesfeld A, Goetz K. Integrated care in German mental health services as benefit for relatives-a qualitative study. BMC psychiatry. 2016;16(1):1. https://doi.org/10.1186/s12888-016-0760-6 PMid:26921216 PMCid:PMC4769565

28. Shamsaei F, Cheraghi F, Esmaeilli R. The Family Challenge of Caring for the Chronically Mentally Ill: A Phenomenological Study. Iranian journal of psychiatry and behavioral sciences. 2015;9(3). https://doi.org/10.17795/ijpbs-1898

29. Aldhwaihi KAA. Types and Contributing Factors of Dispensing Errors in Hospital Pharmacies. 2016.

30. Salmasi S, Khan TM, Hong YH, Ming LC, Wong TW. Medication errors in the Southeast Asian countries: A systematic review. PloS one. 2015;10(9):e0136545. https://doi.org/10.1371/journal.pone.0136545 PMid:26340679 PMCid:PMC4560405

31. Nath SB, Marcus SC. Medical errors in psychiatry. Harvard review of psychiatry. 2006;14(4):204-11. https://doi.org/10.1080/10673220600889272 PMid:16912006

32. Javidan M, Dastmalchian A. Culture and leadership in Iran: The land of individual achievers, strong family ties, and powerful elite. The Academy of Management Executive. 2003;17(4):127-42. https://doi.org/10.5465/ame.2003.11851896 